2 The effect of personality traits on consumers' preferences for extra virgin olive oil

4

6

7 a CREDA-UPC-IRTA “The Center for Agro-food Economy and Development"

8 Parc Mediterrani de la Tecnologia Edifici ESAB C/Esteve Terrades, 808860 Castelldefels,

9 Barcelona, Spain.

10

11 E-mail addresses: Ahmed.yangui@upc.edu; montserrat.costa-font@upc.edu;

12 chema.gil@upc.edu

13

14 *Corresponding autor: GIL José Maria

15

16 Tel: +34935 521210

17 E-mail addresses: chema.gil@upc.edu

18 CREDA-UPC-IRTA "The Center for Agro-food Economy and Development"

19 Parc Mediterrani de la Tecnologia Edifici ESAB C/Esteve Terrades, 808860 Castelldefels,

20 Barcelona, Spain.

21

22 


\section{The effect of personality traits on consumers' preferences for extra virgin olive oil}

(1)

\section{Introduction}

Olive oil is a food product consumed in most Mediterranean countries and is an essential component of the Mediterranean diet (Garcia-Closas et al., 2006). Its importance in the daily lives of consumers reflects its ancient traditions, its social and agro-environmental dimensions, as well as its health and nutritional benefits. The European Union produces 73 percent of the world's olive oil and consumes about 66 per cent (International Olive Oil Council, 2013). As Figure 1 shows, the main olive oil producers and consumers are Spain and Italy. However, an important expansion of olive oil consumption may be observed outside the traditional Mediterranean countries (United States International Trade Commission, 2013). The Mintel Global New Products Database (GNPD) database reveals that 1,116 new olive oils were launched from 2011 to 2013 all around the world. Of these, stores in the USA stocked about 15 percent, followed by Brazilian stores with about 13 percent (see Table 1).

Olive oil characteristics are regulated within the EU by Regulation (EEC) $\mathrm{N}^{\circ}$ 2568/91, which establishes a list of physical, chemical, and organoleptic characteristics, as well as methods for their measurement. However, continuous research and development (R\&D) in this sector has produced a large variety of olive oil types and specifications, making consumers more dependent on displayed information to make their purchasing decisions. Olive oil quality attributes are mainly communicated on the product label, which builds pre-consumption confidence among consumers (Scarpa and Del Giudice, 2004). Olive oil labels typically fall within the category of "credence attributes," including organic production certifications and protected denomination of origin (PDO), which consumers cannot directly value through consumption of the oil (Nocella et al., 2012).

Understanding oil consumption requires accounting for new olive oil varieties and trademarks developed worldwide and for the increasing public awareness of the health and environmental benefits associated with the Mediterranean diet and PDO products.

However, different consumers may focus on different information cues, and therefore may develop specific behavioral criteria when making purchasing decisions (Menapace 
54 et al., 2011; Philippidis et al., 2002). Hence, better understanding of how consumers

55 evaluate olive oil is essential to help producers succeed in an increasingly competitive 56 market.

57 More understanding of how consumers construct their evaluations and their 58 consequent purchasing decisions with respect to marketed olive oils is also important to 59 EU policy makers and regulators. It is extremely likely that olive oil consumption will 60 increase at world level. The current orientation of EU olive oil policy, as stated in the 61 European Commission web page, ${ }^{1}$ is "to maintain and strengthen its position in world 62 markets by encouraging production of a high quality product for the benefit of growers, processors, traders and consumers.” However, this is not an easy task, as an individual's preferences depend not only on the extrinsic and intrinsic attributes of the products to be purchased but also on factors unrelated to food (Chen, 2007; Nocella et al., 2012).

This paper aims to identify the effect of consumers' specific characteristics, namely the role of food-related personality traits, lifestyle orientations, and purchase habits in shaping their purchase intentions regarding olive oil. To achieve this objective, data from a survey carried out from a representative sample of Catalonian (north-eastern Spain) consumers have been employed. The methodological framework is based on a discrete-choice modeling approach, named the hybrid choice model (HCM). This model specifically accounts for preference heterogeneity in examining the effects of individual personality traits, lifestyles, and habits.

Traditionally, the HCM model has involved two steps. ${ }^{2}$ In the first step, latent variables (i.e., food-related personality traits, lifestyles or purchase habits, among others) are derived from observed indicators via a "multiple-indicator, multiple cause" model (MIMIC), used to relate latent individual traits to observable determinants. In the second step, the predicted latent variables are incorporated into the discrete-choice model as explanatory variables to estimate a multinomial logit model.

\footnotetext{
${ }^{1}$ http://ec.europa.eu/agriculture/olive-oil/index_en.htm

2 Alternatively, the HCM can be seen as resulting in both efficient and consistent estimates (Ben-Akiva et al., 2002; Kløjgaard and Hess, 2011; Rungie et al., 2012). However, this approach usually results in convergence and identification problems, as the number of latent variables increases (Ashok et al., 2002). In this study, due to the high number of latent variables introduced, the sequential estimation method of the HCM based on the mixed logit model is used.
} 
Our paper extends the existing literature in at least two ways. First, it does not

81 merely estimate latent variables from observed indicators, but also estimates the

82 hierarchical relationships between latent variables using a structural equation model

83 (SEM), providing better insight into the consumers' cognitive decision-making

84 processes. Second, this study employs an HCM in a panel-data context constructed from

85 the repeated-choice data set while considering sample heterogeneity. It estimates a

86 random parameter logit (RPL) model, considering the latent variables as random

87 parameters (Yáñez et al., 2010) and solving the HCM problem of integrating the

88 variation of the latent variables within the basic framework of multinomial choice 89 models (Ashok et al., 2002).

90 The paper is structured as follows. Section 2 outlines the methodological 91 framework used-the HCM. The design of the empirical application is shown in 92 Section 3. Specifically, we will concentrate on how the SEM model has been specified 93 and how the choice experiment has been designed. The main results are outlined in 94 Section 4. The final section contains some concluding remarks.

95

96

97

98

99

100

101

102

103

104

105

106

107

108

109

110

\section{Methodological framework: the HCM}

The discrete-choice model approach has received a significant amount of attention in recent literature (Campbell et al., 2010; Greene and Hensher, 2013). Moreover, evidence of preference heterogeneity in both revealed and stated preference data is increasing. Failure to account for preference heterogeneity may result in poor model performance, which could lead to reliability problems in the model results (Hynes et al., 2008). Different methodological approaches have been suggested in the literature: 1) the use of latent class models (McFadden, 1986; Boxall and Adamowicz, 2002); 2) the inclusion of interaction effects to explain sources of heterogeneity (Montgomery, 2001); 3) the use of random parameter estimates, assuming preference coefficients to be randomly distributed across individuals (Revelt and Train, 1998; Walker and BenAkiva, 2002); and 4) the combination of interaction effects and random parameters (Hensher and Greene, 2003) or latent class and random parameters (Bujosa el al., 2010; Greene and Hensher, 2013).In all cases, individuals' utilities and the heterogeneity of their preferences are assumed to be a function of the observed variables. However, these 
111 observable product attributes and covariates can only explain part of the utility, and fail

112 to capture the true inner process of a decision maker.

113 Ben-Akiva et al. (2002) extended the traditional discrete-choice model by 114 introducing the HCM. The HCM model defines an individual's utility as a function of 115 observed explanatory variables, such as product attributes and respondents' socio116 economic characteristics, while including latent variables that can reflect consumers' 117 psychological factors, personality traits, or attitudes. Previous empirical applications of 118 the HCM have been mainly in the field of transport economics (Bolduc et al., 2008; 119 Yáñez et al., 2010), and recently in sociology (Rungie et al., 2011, 2012) and health 120 economics (Kløjgaard and Hess, 2011). They have shown that: 1) the inclusion of latent 121 variables significantly improves the goodness-of-fit of the model; and 2) psychological 122 factors better contribute to capturing a consumer's preference heterogeneity. One of the 123 main contributions of this study is that it constitutes one of the first attempts to apply 124 the HCM approach to food marketing.

125 The application of the HCM implies the design of a choice experiment, which is 126 based on both random utility theory (RUT) (McFadden, 1974) and Lancaster consumer 127 theory (Lancaster, 1966). The RUT assumes that the utility provided by alternative $j$ $128(j=1, \ldots, J)$ from choice set $s(s=1, \ldots, S)$ to individual $i \quad(i=1, \ldots . N)$ is given by the 129 following:

$130 U_{i j s}=V_{i j s}+\varepsilon_{i j s}$

131 where $V_{i j s}$ is a deterministic component and $\varepsilon_{i j s}$ is the stochastic or non-observed 132 component. In a traditional model, the deterministic component, $V_{i j s}$, can be represented 133 as a function of alternative attributes as follows:

$134 V_{i j s}=\beta_{i k j s} * X_{k j s}$

135 where $X_{k j s}$ is the vector of attributes related to alternative $\mathrm{j} ; \beta_{i k j s}$ is the vector of 136 marginal utilities of the individual $i$ related to the $k$ attributes in alternative $j$ from the 137 choice set $s$.

138 In the HCM, latent variables are incorporated in the deterministic component of an 139 individual's utility $V_{i j s}$ as follows:

$140 V_{i j s}=\beta_{i k j s} * X_{k j s}+\beta_{l i j s} * \eta_{l i j s}+\beta_{q i j s} * \xi_{q i j s}$ 
141 where $\eta_{l i j s}$ is the vector of endogenous latent characteristics $(l=1, \ldots . L), \xi_{q i j s}$ is the 142 corresponding vector of exogenous latent characteristics $(q=1, \ldots, Q)$; and $\beta_{\text {lijs }}$ and $\beta_{q i j s}$ 143 are the vectors of the marginal effects of $\eta_{l i j s}$ and $\xi_{q i j s}$ on the utility function of the $i$-th 144 individual when choosing alternative $j$ from the choice set $s$.

145 However, these latent variables are immaterial constructs that cannot be directly 146 observed: the usual approaches to identifying them rely on MIMIC or SEM models. 147 Both require additional information about these latent variables (i.e. personality traits, 148 purchase habits, or lifestyles). The MIMIC model considers only a group of latent 149 variables that are explained by a set of observable determinants. The SEM also takes 150 into account the structural relationships that can exist among latent variables.

The SEM consists of two sets of equations. The first, a set of measurement 152 equations, describes the relationship between latent (exogenous $\xi_{\text {qijs }}$ and 153 endogenous $\left.\eta_{l i j s}\right)^{3}$ and observed variables ( $w_{\text {pijs }}$ and $x_{m i j s}$ ), after performing a 154 confirmatory factor analysis (Equations 4 and 5) (Jöreskov and Sörbomm, 1996). The 155 second, a set of structural equations, describes the relationship between endogenous and 156 exogenous latent variables, and permits the evaluation of the causal effects among these 157 variables (Equation 6) (Jöreskov and Sörbomm, 1996).

$$
\begin{aligned}
& x_{m i j s}=\Lambda_{m q i j s} \xi_{q i j s}+\delta_{m i j s} \\
& w_{p i j s}=\Lambda_{\text {plijs }} \eta_{l i j s}+\Gamma_{p i j s} \\
& \eta_{l i j s}=\alpha_{l i j s} \eta_{l i j s}+\theta_{l i j s} \xi_{q i j s}+\zeta_{l i j s}
\end{aligned}
$$

161 where the indices $m, p, l, q, i, j$, and $s$ refer to indicators that describe exogenous latent 162 variables, indicators that describe endogenous latent variables, endogenous latent 163 variables, exogenous latent variables, respondents, alternatives, and choice sets, 164 respectively. $\Lambda_{m i j s}, \Lambda_{p i j s}, \alpha_{l i j s}$, and $\theta_{\text {lijs }}$ are the parameters to be jointly estimated. $165 \delta_{m i j s}, \Gamma_{p i j s}$, and $\zeta_{l i j s}$ represent the error terms that are typically considered normally 166 distributed with mean zero and standard deviation to be estimated, and assumed to be

\footnotetext{
${ }^{3}$ The term "exogenous latent variable" means that it is not dependent on any other variable in the model. Usually one or more variables in the model are dependent on this variable. Endogenous latent variables refer to latent variables that are dependent on one or more variables in the model. Note that an endogenous variable may be dependent on another endogenous variable.
} 
167 uncorrelated with $\xi_{q i j s}, \eta_{l i j s}$, and both $\xi_{q i j s}$ and $\eta_{l i j s}$, in Equations 4, 5, and 6, 168 respectively. The Full SEM model is estimated with Robust Maximum Likelihood 169 (RML), due to a potential lack of normality.

170 Now, the probability of consumer $i$ choosing the alternative $j$ from the choice set $\mathrm{s}$, 171 assuming that the stochastic component $\varepsilon_{i j s}$ follows the type I Extreme Value 172 distribution, is defined as follows:

$173 \quad P_{i j s}=\frac{\exp \left(\mu V_{i j s}\right)}{\sum_{t=1}^{J} \exp \left(\mu V_{i t s}\right)}$

174 The sequential estimation method of the HCM requires integrating over the 175 variation of latent variables within the basic framework of multinomial choice models 176 (Ashok et al., 2002). Yañez et al. (2010) showed that this integration could be attained 177 by estimating an RPL model that considers the latent variables as random parameters.

178 Under the RPL model, the probability that individual "i” chooses alternative "j" 179 from a particular choice set $\mathrm{s}$ is given by the following:

$180 P_{i j s}=\int L_{i j s}\left(\beta_{i j s}\right) f\left(\beta_{i} \mid \theta\right) d \beta_{i}$

181 where $f\left(\beta_{i} \mid \theta\right)$ is the density function of the $\beta_{i}$ coefficients, and $\theta$ refers to the moments 182 of the parameter distributions, which can take any specified form, such as normal, 183 lognormal, triangular, uniform, etc. Moreover,

$184 L_{i j s}\left(\beta_{i j s}\right)=\frac{\exp \left(V_{i j s}\left(X_{i j s}, \eta_{l i j s}, \xi_{q i j s}, \beta_{i}\right)\right)}{\sum_{t=1}^{J} \exp \left(V_{i t s}\left(X_{i t s}, \eta_{l i t s}, \xi_{q i t s}, \beta_{i}\right)\right)}$

185 The parameter estimates $\beta_{i j s}$, are defined to capture additional non-observed 186 variations and to better explain preference heterogeneity between individuals, as follows 187 (Hensher et al., 2005):

$188 \beta_{i j s}=\beta_{j s}+\delta_{j s} Z_{i}+\sigma_{j s} \vartheta_{i j s}$

189 where $\beta_{j s}$ is the sample-mean for the alternative $j$ from the choice set $\mathrm{s}$; $\vartheta_{i j s}$ is the 190 individual specific heterogeneity, with mean zero and standard deviation equal to 1 191 (Hensher and Greene, 2003); and $Z_{i}$ is a set of choice invariant characteristics that 192 produce individual heterogeneity in the means of the randomly distributed coefficients, 193 such as individual specific characteristics. 
Because the resulting model is specified to include both fixed and random

195 coefficients, the simulated maximum likelihood (SML) technique provides a faster and

196 easier way to estimate the individual choice probabilities (Ben-Akiva et al., 2002).

197 According to Train (2003), the simulation proceeds in three steps for any given value of

$198 \theta$. First, a value of $\beta_{i}$ is drawn from $f\left(\beta_{i} \mid \theta\right)\left(\beta_{i}^{r}\right.$ with $\left.r=1 \ldots \mathrm{R}^{4}\right)$. Second, the logit

$199 L_{i j s}\left(\beta_{i}^{r}\right)$, is calculated from this draw. Finally, Steps 1 and 2 are repeated, and the

200 obtained results are averaged. This average is the simulated probability:

$201 \widehat{P_{l \jmath S}}=\frac{1}{R} \sum_{r=1}^{R} L_{i j s}\left(\beta_{i}^{r}\right)$

202 where $\mathrm{R}$ is the number of draws. The simulated probabilities are inserted into the log-

203 likelihood function to give a simulated log-likelihood (SLL):

$204 S L L=\sum_{i=1}^{I} \sum_{j=1}^{J} d_{i j s} \ln \widehat{P_{l J S}}$

205 where $d_{i j s}=1$ if $\mathrm{i}$ chooses $\mathrm{j}$ from the choice set $\mathrm{s}$ and $d_{i j s}=0$ otherwise. The maximum

206 simulated likelihood estimator, (MSLE), is the value of $\theta$ that maximizes SLL.

207

208

209

210

211

212

213

214 215 and value (International Olive Oil Council, 2013). Additionally, olive oil constitutes a

216 fundamental component of the Spanish diet.

217

218

219

\section{The experiment design}

\subsection{The survey}

The data used in this study were obtained from a survey carried out on a representative sample of the Catalonian (north-east Spain) population with quotas by postal code. The survey was addressed to those responsible for shopping within the household. The Spanish market was selected because Spain is top-ranked together with

Italy among those countries producing and exporting olive oil, in terms of both quantity fundamental component of the Spanish diet.

As a consequence, many Spanish consumers are knowledgeable about this product, and most of them are aware of market prices and product characteristics. In Spain, the market value for organic olive oil was 5.4 million Euros in 2012 (MAGRAMA, 2013).

\footnotetext{
${ }^{4}$ Halton draws were used because they have been shown to provide more efficient distributions for numerical integration compared to random draws (Bhat, 2003).
} 
Catalonia is second among Spanish regions in terms of total olive oil consumption,

221 with a per capita consumption of 9.93 liters in 2011. It also occupies the second position

222 in relation to the consumption of organic olive oil (13 percent of the Spanish total

223 consumption in value) after Madrid. The population in Catalonia is quite heterogeneous,

224 with a combination of urban (Barcelona is the second-largest city in Spain) and rural

225 environments.

226 Information was gathered from 401 persons. Participants were recruited using two

227 filters: 1) they had to have bought extra-virgin olive oil in the last three months; and 2)

228 they were responsible for shopping within the household. Face-to-face interviews were

229 conducted in September 2009 at different shopping hours and different types of food

230 retail stores. The questionnaire consisted of four major blocks. The first block was

231 designed to elicit information on respondents' purchasing and consumption habits with

232 regard to different types of olive oil. The second and third blocks were reserved to

233 obtain the latent variables and to collect information about socio-demographic

234 characteristics and consumers' personality traits and lifestyles. All indicators were

235 measured using eleven-point Likert scales (from 0 to 10, where 0 indicates total

236 disagreement and 10 is total agreement). ${ }^{5}$ The last block included the choice experiment

237 task.

238

\subsection{A conceptual model for organic olive oil purchasing intention}

240

241

242

The first step in the HCM consists of defining the latent variables that will be introduced later in the discrete-choice model. In this paper, latent variables have been measured through a set of observable indicators, and the hierarchical relationships between the latent variables have been estimated using an SEM. In this section, the conceptual model on which the SEM is based is presented. Based on previous literature, we will define the main latent variables used for the purpose of this paper as well as the expected relationships between them.

\footnotetext{
${ }^{5}$ Respondents can easily understand this scale, as the grading system at Spanish schools is based on a similar system.
} 
Previous studies have highlighted the importance of attitudes and perceptions in 248 understanding the decision-making process during purchase (Ajzen, 2005; Ben-Akiva et 249 al., 2002; Eertmans et al., 2005; Johansson et al., 2006; Scarpa and Thiene, 2011). 250 Several studies have found that a relationship exists between an individual's personality 251 traits, psychological characteristics, or attitudes to nutrition (Chen, 2007; Nocella et al., 252 2012).

In view of these results, the conceptual model we use draws on the Theory of 255 variables to be introduced in the discrete-choice model (Ashok et al., 2002). As Ajzen 256 (1991) has stated, the TPB was designed to predict and explain human behavior in 257 specific contexts based on the relation between intention and behavior, so that intentions 258 to perform a behavior (such as purchasing olive oil) are assumed to capture the 259 motivational factors that influence such behavior. The TPB considers that human 260 intentions to perform a behavior are guided by three types of consideration: 1) the 261 "attitude" toward the behavior, or to what extent a person evaluates, either positively or 262 negatively, the behavior in question; in the case of organic food, a positive attitude 263 toward organic food is believed to be positively related to the intention to purchase 264 organic food (Chen, 2007); 2) “subjective norms” or perceived social pressure, such as 265 from family, friends, etc. to perform or not to perform the behavior (Ajzen, 1991, Al266 Swidi et al. 2014); and 3) beliefs about the presence of factors that may facilitate or 267 impede the performance of the behavior. The power of these control beliefs determines 268 the "Perceived Behavioral Control" or perceived ease or difficulty of performing the 269 behavior. In the framework of organic food, perceived control would include the effects 270 of both external (such as time spent, availability, recognition by labeling, confidence, 271 etc.) and internal variables (such as skills, knowledge, abilities, habits, etc.) that 272 consumers believe can influence their judgment of risks and benefits associated with 273 these products (Ajzen, 2005; Chen, 2007).

274 In the specific case of purchasing organic olive oil we can test the hypothesis that 275 attitudes toward organic olive oil, subjective norms regarding olive oil, and the 276 Perceived Behavioral Control in purchasing olive oil lead to the formation of a final 277 behavioral intention to purchase. Figure 2 shows the conceptual model used in this 278 study. Our model extends the TPB in two ways: identifying which personality traits 
279 have an effect on shaping individuals' attitudes toward the behavior; and testing if 280 extrinsic product features, such as available information, quality evaluation, and price can have an effect on facilitating the perception of control toward the behavior.

Chen (2007) showed that food-related personality traits, defined as food involvement or the level of importance that food has in a person's life (and operationalized as the extent to which people enjoy talking about food, entertain thoughts about food during the day, and engage in food-related activities: Goody, 1982), exert a positive effect on a consumer's attitude toward organic food. Bell and Marshall (2003) argued that the level of food involvement was a significant discriminating factor between food items in sensory evaluations. Eertmans et al. (2005) argued that both food intake and following a healthy diet appeared to vary with level of food involvement. Therefore, the following hypothesis is proposed:

Hypothesis 1a. Consumers who show a higher level of food involvement are expected to have a more positive attitude toward organic olive oil than consumers who give less importance to food.

Food-related personality traits link people to food-related activities, such as food procurement, preparation, cooking, etc. (Goody, 1982). The recent literature shows that cooking skills play a significant role in dietary changes to promote healthy eating (Van den Horsk et al., 2010). Due to the importance of olive oil in the Mediterranean diet, cooking skills are hypothesized to affect the attitude toward organic olive oil positively. Thus, the following hypothesis is proposed:

Hypothesis $1 \mathrm{~b}$. Consumers with better cooking skills are expected to have a more positive attitude toward organic olive oil than consumers with fewer cooking skills.

Another factor that has been emphasized as an important psychological variable in describing consumer food choice is lifestyle. Different lifestyles sort individuals into groups on the basis of the things they like to do, how they like to spend their leisure time, and how they choose to spend their disposable income (Moore, 1963; Krishnan, 2011). Lifestyle describes how people seek to express their identity in many areas, such as activities, interests, and opinions (Wells and Tigert, 1971). In a consumption environment, a person chooses a product or brand that seems to match with his/her life style/identity (Krishnan, 2011). An individual's lifestyle is reflected in his/her 
310 personality and self-concepts, which are determined by his/her interests, opinions, 311 activities, etc.

312 Moreover, attitudes, behavioral tendencies, and habits are derived from differences 313 in lifestyles across consumers (Chen, 2009). Shaharudin et al. (2010) showed that 314 consumers' lifestyles were related to their attitude toward the purchasing of organic 315 food. Krishnan (2011) confirmed that consumers' lifestyles were strongly related to 316 their purchased brands. Our model aims to identify two types of consumer lifestyle: 317 healthy lifestyle and orderly lifestyle. The former emphasizes physical health-related 318 activities, such as natural food consumption, health care, etc. (Gil et al., 2000). 319 Eertmans et al (2005) argue that a healthy lifestyle should be advocated to render the 320 consumer's attitude toward organic foods more positive. The orderly and methodical 321 lifestyle can be expressed through activities such as disposing garbage in different 322 containers, reducing stress, keeping equilibrium between working and personal life, et 323 cetera. Therefore, the following hypothesis is proposed:

324 Hypothesis 1c: Consumers with orderly lifestyles can more easily follow 325 environmentally friendly behaviors and therefore have a more positive attitude toward organic food than consumers who have less orderly lifestyles.

327 Over the last decade, food scares (BSE, dioxins, foot-and-mouth disease, etc.) have 328 reshaped consumer behavior to a certain extent. Consumers are now more concerned 329 about food safety issues (Chen, 2007). Moreover, according to Chen (2009), a healthy 330 consumption lifestyle, attitudes toward organic food, and the intention to purchase 331 organic food appear to correlate significantly. Therefore, the following hypothesis is 332 proposed:

333 Hypothesis 1d. The healthier the consumers' lifestyle, the more positive their 334 attitudes toward organic foods will be.

335 As stated before, extrinsic product features, such as available information, and 336 purchasing habits such as quality and price valuation, can have an effect on facilitating 337 the perception of control toward behavior. Indeed, Ajzen (2005) stated that the more 338 resources and opportunities individuals believe they possess, and the fewer obstacles or 339 impediments they anticipate, the greater should be their perceived control over the 340 behavior. Therefore, the following hypothesis can be proposed: 
Hypothesis 2a. With more information that consumers have regarding a product,

342 such as its certification (labels), the greater should be the control they perceive to have 343 regarding the specific acquisition.

344 Repetitive purchasing habits can simplify behavior, as many decisions become 345 routine and can be adopted with minimal conscious control. In other words, individuals 346 tend to persist in doing what they have are accustomed to doing. In this study, we have 347 assessed the effect of "purchasing habits" by considering two latent variables, "Price 348 Involvement” and "Quality Involvement," which have been considered by other authors 349 to be relevant in explaining consumer buying behavior (Mann et al., 2012; Menapace et 350 al., 2011). The first variable involves the relevance of price and price promotions in a 351 specific purchasing decision. As shown by Avitia et al. (2015) the price has a highly 352 relevant role in defining consumers' willingness to purchase sustainable food, and it can 353 be considered as a limit for current consumption of sustainable food. Their work 354 indicated that consumers value sustainable attributes and are willing to pay a premium 355 for them, but this premium is still lower than the market price for such products. The 356 same can be said in relation to quality standards. Therefore, the following hypotheses 357 can be proposed:

358 Hypothesis $\mathbf{2 b}$. As consumers become less sensitive to price and price promotions, 359 their perceived behavioral control increases.

360 Hypothesis 2c. As food quality plays a more important role in consumers' food 361 habits, their perceived behavioral control increases. of the brand) with three levels each were used in the experiment design (Table 2). The

366 attribute and attribute levels were selected based on a three-step qualitative study: 1) a 367 literature review of consumer behavior relating to organic and/or extra virgin olive oil; 368 2) four focus groups of eight people each were conducted to identify the main 369 consumption patterns and attitudes toward extra virgin olive oil, with special attention 370 to the organic attribute; and 3) observation in retail outlets to identify real prices and 
371 informal interviews in the same retail outlets about reasons for choosing a specific 372 product.

373 Considering the number of attributes and their levels in Table 2, a full factorial 374 design of $81\left(3 * 3 * 3 * 3=3^{4}\right)$ combinations was generated. Presenting respondents with 375 one-liter bottles of olive oil with 81 combinations of attributes, however, could place a 376 high level of cognitive burden on respondents. To reduce the number of combinations

377 that participants had to evaluate, we followed Street and Burgess (2007) and generated 378 an orthogonal fractional factorial design of nine combinations. These nine combinations 379 were considered as the first option in each choice set. Since participants were provided 380 with choice sets of three options each (plus a no-choice option), the other two options 381 were obtained using the following generators (1212) and (2121) (Street and Burgess, 382 2007). This resulted in a 100 percent efficient main-effects design.

\section{Results and discussion}

\subsection{Sample characteristics}

As mentioned above, a total of 401 respondents completed the survey. About 80 percent were women, consistent with statistics reported by the Spanish ministry about shopping responsibility within the household (MAGRAMA, 2008). Approximately 70 percent of the respondents were married, and their average age was 49 years (with a standard deviation of 15.39). The average household size was three. Furthermore, 35 percent were households with one or more members younger than 18 years old, and only 14 percent had children under six years old. Regarding education level, 27.3 393 percent of respondents had only completed primary school, while 46.8 percent had 394 completed secondary studies or professional education. Finally, regarding the 395 geographic distribution of the sample, 40 percent came from Barcelona (the Catalonian capital), while 60 percent came from the rest of the Catalonian region.

397 Consistent with Jiménez-Guerrero et al. (2012), results from the survey suggest 398 that most respondents usually purchase extra virgin olive oil, but only 9.25 percent of 399 the respondents search for PDO extra virgin olive oil. Olive oil is normally purchased 400 weekly or every two weeks, although a significant percentage of respondents (nearly 30 401 percent) purchase it monthly or quarterly (in many cases directly from a 
402 farmer/producer or a cooperative). The consumption of organic olive oil is marginal

403 (less than 0.6 percent of respondents buy it regularly). Respondent's reasons for not 404 buying organic olive oil included the high price, the lack of availability in the 405 supermarket where they buy food, or lack of information about organic food.

406

407

408

409

410

411

412

413

414

415

416

\subsection{The SEM: Consumer's purchasing intentions}

Following the traditional procedure for estimating the SEM (Kline, 2005), a confirmatory factor analysis (CFA) was first carried out for the entire set of constructs. Six "personality latent variables" (orderly life style, healthy life style, price involvement, food quality involvement, food involvement, and cooking skills) and five "behavioral latent factors” (attitude, behavioral control perception, purchase intention, knowledge, and subjective norms) were obtained (Tables A1 and A2, in the Annex). Standardized factor loading estimates were all significant and above the recommended value of 0.7 (Hair et al., 1999). The main parameters to test the robustness of the construct, following Kline (2005), appear to show good results for almost all constructs. The internal consistency of reliability of each construct reached an acceptable Cronbach alpha of over 0.7 , and the composite reliabilities were greater than 0.7 , except for the factor "Healthy Life Style”, which was 0.6. Nevertheless, we chose to retain this factor in our model.

The SEM was estimated in the second step. Table 3 summarizes the estimation results and the main goodness-of-fit measures. The model meets the accepted goodnessof-fit criteria according to Hair et al. (1999) and Kline (2005): 1) the normed Chisquared (NC) is less than $3 ; 2$ ) the value for the root mean square error of approximation (RMSEA) is 0.065 (less than 0.8); 3) regarding the incremental fit-index, the comparative-fit-index (CFI) is 0.952, which exceeds the value guidelines in the literature $(0.90) ; 4)$ the normed-fit-index (NFI), non-normed-fit-index (NNFI) and relative fit-index (RFI) are all above 0.9, indicating that the conceptual model adequately fits the data; and 5) the adjusted $R^{2}$ values are reasonably high for this type of model.

Results from Table 3 indicate that both consumers' social pressure (subjective norms) and their Perceived Behavior Control positively affect consumers' intentions to purchase organic olive oil, consistent with Chen (2007). However attitudes toward organic olive oil are negatively related to organic olive oil purchasing intention. This 
434 result is not surprising. There are two arguments supporting it. First, Avitia et al. (2015)

435 showed that although Spanish consumers valued the sustainable food attribute they were 436 not willing to pay a premium for this attribute. Second, in the specific case of olive oil, 437 Spanish consumers do associate extra virgin olive oil with health and sustainable 438 characteristic irrespective of the type of production system (organic or conventional) 439 (Calatrava, 2002 and Vega-Zamora et al., 2011), making differentiation between the 440 two types of olive oil more difficult.

441 Furthermore, only the variables "Food Involvement" and "Orderly Lifestyle" 442 positively affect attitudes, which supports Hypotheses 1a and 1c., corroborating Chen 443 (2007) and Bell and Marshall (2003), who state that consumers with higher food 444 involvement personality traits have a more positive attitude toward organic food and are 445 better able to discern healthier foods. Additionally, results reveal that an orderly 446 lifestyle seems to enhance an individual's attitude toward organic olive oil. Gracia and 447 Magistris (2008) obtained similar results, suggesting that consumers trying to follow an 448 orderly life are more likely to develop environmentally friendly attitudes and follow a 449 healthier diet in which olive oil plays an important role.

450 On the other hand, the relationships between attitudes, cooking skills, and healthy 451 lifestyles are not significant (Hypotheses $1 \mathrm{~b}$ and $1 \mathrm{~d}$ are not supported). In both cases, 452 this result is related to the perception of conventional olive oil as a healthy product, 453 which already plays an important role in the Mediterranean diet. Organic olive oil is not 454 perceived as healthier than its conventional counterpart, as mentioned above.

“Knowledge,” “Food Quality Involvement,” and “Price Involvement” significantly and positively affect consumer's Perceived Behavioral Control, which supports Hypotheses 2a and 2c but rejects Hypothesis 2b. Although the standardized factor loading of "Price Involvement" was significantly different from zero, its positive coefficient led us to reject its associated hypothesis (2b). This finding is consistent with

460 Eertmans et al. (2005), who stated that price was negatively related to healthy diet.

\subsection{The choice model: consumer's preferences for olive oil attributes}

The second step in the HCM consists of estimating an RPL model that incorporates 463 latent variables (LV) obtained from the SEM. The estimated utility function includes all 464 attribute levels defined as effect-coded, except the price attribute, which is introduced as 
465 a continuous variable as well as LVs. Socio-demographic variables, such as gender 466 (GEND), age (AGE) and town size (TS), are defined as dummy variables (1 467 representing women, age less than 50 years, and town size over 10000 inhabitants, 468 respectively). The education level includes three categories: university degree (UNIV), 469 completed secondary school (SECOND) and primary school. Thus, two effect-coded 470 dummy variables were defined. The first one was university degree (UNIV), which took 471 the value 1 if the respondent had a university degree, 0 if the respondent has completed 472 secondary school, and -1, otherwise. The second education dummy was having 473 completed secondary school (SECOND), which took the value 1 if the respondents had 474 completed secondary school, 0 if the respondent had a university degree, and -1 , 475 otherwise. Finally, all random parameters were assumed to be normally distributed.

Table 4 shows the estimated parameters from the RPL model. The no-option 477 coefficient is negative and significant, which indicates that most of the respondents 478 participated in the choice experiment by choosing one of the proposed olive oil 479 alternatives instead of the no-option. The results also reveal that the organic attribute 480 generates a disutility to consumers, while the most preferred olive oil is the one 481 produced under a PDO. In line with Calatrava (2002), the organic attribute does not 482 represent any additional value to Spanish consumers.

483 This finding contradicts the results reported in other studies, such as Gracia and 484 Magistris (2008) for Italy, Soler et al. (2002), and Vega-Zamora et al. (2011) for Spain, 485 or Tsakiridou et al. (2006) for Greece. However in these studies, consumers were only 486 required to choose between organic olive oil and its conventional counterpart, whereas 487 we have considered the trade-offs not only with other olive oil attributes but also with 488 other attribute levels within the production system (i.e., PDO) in our study. Moreover, 489 environmental concerns are not a key factor in a consumer's food choices, especially in 490 the case of olive oil (Vega-Zamora et al., 2011).

491 Contrary to the organic attribute, Catalonian consumers show a strong preference 492 for PDO extra virgin olive oil. PDO extra virgin olive oil is well known among 493 Catalonian and Spanish consumers. Twenty-eight PDO brands exist in Spain, and five 494 of them are located in Catalonia. Additionally, the production of this type of olive oil 495 continues to grow; the domestic market and, to a lesser extent, the EU are its main 496 destinations (Ruiz-Castillo, 2008). 
The results further reveal that the price parameter is negative and significant (Menapace et al., 2011; Vega-Zamora et al., 2011). The local origin of olive oil plays an important role in shaping consumer's preferences in Catalonia. Catalan olive oils are preferred over other Spanish or imported oils, while olive oil produced in other Spanish regions is preferred over imported olive oil, as in Jiménez-Guerrero et al. (2012). In contrast, the specific brand did not significantly impact consumers' utilities, which indicates that respondents are more interested in the origin of extra-virgin olive oil than in the origin of the brand. This result could be related to the fact that many consumers do not recognize the origin of the brand (that is, whether the manufacturer is located or not in Catalonia). The results also show that consumers do not value private labels for this specific product in general.

Interestingly, almost all personal trait LVs (except orderly lifestyle) significantly affected the respondents' preferences for extra virgin olive oil (Table 4). In line with previous results, we note that the sign of the variable "Healthy Lifestyle" is negative and significant. Consistent with previous results about the organic attribute, a healthy lifestyle is not related to the selection of olive oil, although healthy lifestyles may be conducive to healthier food choices (Losasso et al., 2012). In Catalonia, olive oil is perceived as a key feature of the traditional Mediterranean diet, and is widely used by consumers independently from their particular cooking habits or diets. This fact also can explain the negative sign of the coefficient related to the variable "Cooking Skills”.

The other three variables, “Food Involvement”, “Price Involvement”, and “Quality Involvement” positively affect consumers’ preferences for extra virgin olive oil (Table 4). A large number of extra virgin olive oil options are available in Catalonian markets, which can accommodate a broad range of preferences. People looking for good prices can easily meet their preference either by buying directly from the producer or cooperative (30 percent of our sample) or by choosing a promoted product at a retail outlet. Those looking for quality can also easily fit their preference.

Table 4 (middle part) shows that the standard deviations of all relevant attributes and personal traits are significant, which indicates heterogeneity in the preferences of Catalonian consumers. The negative effect of healthy lifestyles on consumers' preferences is not homogeneous across the sample. In fact, the negative coefficient becomes positive for women and younger people. The negative effect is mitigated for 
respondents that have completed secondary school, but increases for people living in larger towns. The negative effect of cooking skills is mitigated in the case of women and well-educated people.

The positive effect of food involvement on consumer's utility increases for women and the highest educated population, but it becomes negative for younger respondents. The positive effect of "Price Involvement" is mitigated for women and the bettereducated population, but significantly increases for people living in larger towns. The positive effect on the consumer's quality involvement when shopping is mitigated in larger towns and, practically disappears in the case of women.

Finally, behavioral LVs affect the utility assigned to the organic attribute. However, this attribute negatively affects the utility of consumers, as mentioned above. The interaction parameters found at the lower part of Table 4 indicate that this negative effect is partially mitigated in consumers affected by subjective norms or with a positive attitude toward organic food. Nevertheless, the organic attribute does not seem to play a significant role in the extra virgin olive oil market.

\section{Conclusions}

The use of limited information models, such as conventional choice models, could be problematic if the decision-making process is strongly conditioned by consumers' personality traits and lifestyles. In this paper, an HCM was applied to understand the consumer's behavioral process related to the purchase of extra-virgin olive oil in Catalonia. Special attention was paid to the organic attribute of the oil. This approach has been proven to be flexible enough to investigate the effect of consumers' foodrelated personality traits, lifestyles, and purchasing habits on their purchase intentions regarding organic olive oil as well as to ascertain the main determinants of consumer choice when buying extra-virgin olive oil.

The results from this study suggest that almost all personal trait LVs significantly affect respondents' utilities toward extra virgin olive oil. "Healthy lifestyle" is significantly but negatively associated with extra virgin olive oil utility, which shows that olive oil preferences in Catalonia respond more to dietary traditions than to healthy food choices. Nevertheless, this result was not homogeneous across the sample. In fact, 
560 the negative effect of "Healthy Lifestyle" was mitigated in women. This result shows

561 that this population segment cares more about diet and the impact of food on health and 562 thus bases its food choices on health reasons.

$563 \quad$ Food-related activities (cooking skills) are more related to social and personal 564 activities than to healthy food measures. Extra virgin olive oil is normally used in 565 Catalonia for salads, boiled vegetables, or grilled food. People with superior cooking 566 skills attempt to use alternative products to traditional olive oil.

567 The variables "Price Involvement” and "Quality Involvement” also significantly 568 and positively affect the respondents' attitudes toward extra virgin olive oil. These 569 factors are both associated with the "Perceived Behavioral Control" construct, 570 expressing the importance of available resources and opportunities in reinforcing 571 consumers' perceptions. However, the effect of these two variables is not homogeneous. 572 Significant differences were found for people living in larger towns. While the overall 573 positive effect of "Price Involvement" increases in larger towns, the positive effect of 574 “Quality Involvement” is significantly mitigated.

575 The results also suggest that Catalan consumers perceive a disutility from the 576 organic attribute compared to other production system alternatives (conventional and 577 PDO). The price is not a relevant factor to explain this result, as organic olive oils are 578 cheaper than PDO olive oils on average. Environmental or health concerns seem not to 579 be relevant to consumers' choices related to olive oil. The organic attribute is not 580 perceived as a significant quality cue, whereas people looking for quality select PDO 581 extra virgin olive oil. This result suggests that traditional marketing strategies that have 582 been used in Catalonia to promote the consumption of olive oils based on environmental 583 or health issues are not effective.

584 The results also indicate that the role of policy makers in the Spanish olive oil 585 sector should be re-assessed. In June 2012, the Commission launched an action plan for 586 the EU olive oil sector, which established six main areas among which quality control 587 and promotion were included. During the last few years in Spain there has been a 588 "premiumization" of olive oil, with the introduction of significant innovations in 589 varieties, packaging, etcetera. These innovations have been the focus of promotional 590 campaigns jointly financed by producer organizations and public institutions to increase 591 consumers' awareness of the health benefits of olive oil. These campaigns have been 
592 proven to be effective in export markets but have not been a commercial success in the 593 domestic market.

594 This study has shown the relevance of behavioral control on shaping consumers 595 intentions toward olive oil. Policy actions on improving consumers' perception of 596 control on the olive oil market seem to be needed in Spain. Olive oil is part of the 597 Spanish culture, but this does not mean that consumers have a good knowledge of types 598 of olive oil, quality grades, etc. Public institutions should provide more information in 599 an increasingly differentiated market. If policy makers aim at promoting sustainable 600 production of olive oil for the domestic market the attributes "Organic" and "Local" 601 should be reinforced with appropriate information campaigns about the characteristics 602 of these attributes and adequate control mechanisms should be in place to strengthen 603 authenticity and protect consumers.

604 The results of this study reinforce the need to include the psychological 605 characteristics of consumers, such as attitudes, food-related personality traits, purchase 606 habits, and lifestyle orientation, to explain how individuals make food choices and to 607 understand their decision-making processes. These findings are likely to encourage a 608 more widespread application of the HCM in the agro-food marketing field. From a 609 methodological point of view, more research should be addressed to providing new 610 tools to estimate the HCM while considering heterogeneity across individuals.

\section{Acknowledgements:}

613 We are very grateful for comments by the editor and referees, which have 614 contributed to improving this paper.

\section{References}

617 Ajzen, I. (1991). The theory of planned behavior. Organizational Behavior and Human 618 Decision Processes, 50 (2), 179-211..

619 Ajzen, I. (2005). Attitude, personality and behavior. (2nd ed.). England: Berkshire. 
Al-Swidi, A., Rafiul Huque, S.M., Haroon, M., Hafeez M., \& Shariff M.N. (2014). The role of subjective norms in theory of planned behavior in the context of organic food consumption, British Food Journal, 116 (10), 1561-80.

Alemán, J.L.M., \& González-Adalid, M.P. (2006). El consumidor europeo de productos ecológicos: primeros resultados de un estudio cualitativo del consumidor español. Distribución y Consumo, 1, 50-64.

Ashok, K., Dillon, W., \& Yuan, S. (2002). Extending discrete choice models to incorporate attitudinal and other latent variables. Journal of Marketing Research, 39, 31-46.

Avitia, J., Costa-Font M., Gil, J., \& Lusk, J.L. (2015) Relative importance of price in forming individuals' decisions toward sustainable food: a calibrated auctionconjoint experiment. Food Quality and Preference, 41, 1-11.

Bhat, C.R. (2003). Simulation estimation of mixed discrete choice models using randomized and scrambled Halton sequences. Transportation Research Part B: Methodological, 37, 837-855.

Bell, R., \& Marshall, D. W. (2003). The construct of food involvement in behavioral research: Scale development and validation. Appetite, 40, 235-244.

Ben-Akiva, M., McFadden, D., Train, K., Walker, J. Bhat, C.A., Bierlaire, M., Bolduc, D., Börsch-Supan, A., Brownstone, D., Bunch, D.S., Daly A., De Palma, A., Gopinath, D., Karlstrom, A., \& Munizaga, M.A. (2002). Hybrid choice models: Progress and challenges. Marketing Letters, 13, 163-175.

Bolduc, D., Boucher, N., \& Alvarez-Daziano, R. (2008). Hybrid choice modelling of new technologies for car choice in Canada. Transportation Research Record, 2082, 63-71.

Boxall, P.C., \& Adamowicz, W.L. (2002). Understanding heterogeneous preferences in random utility models: a latent class approach. Environmental and Resource Economics, 23, 421-446.

Bujosa, A., Riera, A., \& Hicks, R.L. (2010). Combining Discrete and Continuous Representations of Preference Heterogeneity: A Latent Class Approach. Environmental and Resource Economics, 47(4), 477-493.

Calatrava, J. (2002). Actitudes del consumidor español respecto a los productos ecológicos. In Rosua, J.L. (Ed.), Alpujarra: Agricultura y Medioambiente (pp. 89-101). Universidad de Granada Catedra UNESCO. 
Campbell, D., Doherty, E., Hynes, S., \& Rensburg, T.V. (2010). Combining discrete and continuous mixing approaches to accommodate heterogeneity in price sensitivities in environmental choice analysis. Paper presented at the Agricultural Economics Society Annual Conference, Edinburgh, 29 March.

Candel, M.J.J.M. (2001). Consumers' convenience orientation towards meal preparation: conceptualization and measurement. Appetite, 36, 15-28.

Chen, M.F. (2007). Consumer attitudes and purchase intentions in relation to organic foods in Taiwan: Moderating effects of food-related personality traits. Food Quality and Preference, 18, 1008-1021.

Chen, M.F. (2009). Attitude toward organic foods among Taiwanese as related to health consciousness, environmental attitudes, and the mediating effects of a healthy lifestyle. British Food Journal, 111, 165-178.

Eertmans, A., Victoir, A., Vansant, G., \& Van den Bergh, O. (2005). Food-related personality traits, food choice motives and food intake: Mediator and moderator relationships. Food Quality and Preference, 16, 714-726.

Garcia-Closas,R., Berenguer, A., \& González, C. A. (2006). Changes in food supply in Mediterranean countries from 1961 to 2001. Public Health Nutrition, 9, 53-60. doi:10.1079/PHN2005757.

Gil, J.M., Gracia, A., \& Sánchez, M. (2000), Market segmentation and willingness to pay for organic products in Spain. International Food and Agribusiness Management Review, 3(2), 207-26

Goody, J. (1982). Cooking, cuisine and class: a study in comparative sociology. New York: Cambridge University Press.

Gracia, A., \& Magistris, T. (2008). The demand for organic foods in the south of Italy: a discrete choice model. Food Policy, 33, 386-396.

Greene, W.H., \& Hensher, D.A. (2013). Revealing additional dimensions of preference heterogeneity in a latent class mixed multinomial logit model. Applied Economics, 45, 1897-1902.

Hair, J., Anderson, E., Tathan, R., \& Black, W. (1999). Multivariate data analysis with readings. (5th ed.). New Jersey: Englewood Cliffs.

Hensher, D. A., Rose, J.M., \& Greene, W.H. (2005). Applied choice analysis: a primer. New York: Cambridge University Press. 
685 Hensher, D.A., \& Greene, W.H, (2003). Mixed logit models: state of practice. 686 Transportation, 30, 133-176.

687 Hynes, S., Hanley, N. \& Scarpa, R. (2008). Effects on welfare measures of alternative 688 means of accounting for preference heterogeneity in recreational demand models. 689 American Journal of Agricultural Economics, 90, 1011-1027.

690 International Olive Oil Council (IOOC) (2013). Market newsletter December 2013. 691 http://www.internationaloliveoil.org/modules/search. (accessed $20^{\text {th }}$ January, 692 2014)

693 Jiménez-Guerrero, J.F., Gásquez-Abad, J.C., Mondéjar-Jiménez, J.A., \& Huertas694 García, R. (2012). Consumer preferences for olive oil attributes: a review of the 695 empirical literature using a conjoint approach. In Boskou, D. (Ed.) Olive oil696 constituents, quality, health properties and bioconversions. Publisher: InTech.

697 698

Johansson, M.V., Heldt, T., \& Johansson, P. (2006). The effect of attitudes and personality traits on mode choice. Transport Research Part A, 40, 507-525.

Jöreskov, K. \& Sörbom, D. (1996). Lisrel 8: user's reference guide. Scientific software. (2nd ed.). USA.

Kline, R. (2005). Principles and practices of structural equation modeling. New York: Guildford Press.

Kløjgaard, M.E. \& Hess, S. (2011). Understanding the role of practitioners' and patients' perceptions in treatment choices in the face of limited clinical evidence: a Hybrid Choice Model approach, Social Science \& Medicine, 114, 138-150.

Krishnan, J. (2011). Lifestyle - A tool for understanding buyer behavior. International Journal of Economics and Management, 5, 283-298.

Krystallis, A., \& Chryssohoidis, G. (2005). Consumers' willingness to pay for organic food: factors that affect it and variation per organic product type. British Food Journal, 107(5), 320-343.

Lancaster, K. J. (1966). A new approach to consumer theory. Journal of Political Economy, 74, 132-157.

Lea, E., \& Worsley, T. (2005). Australians’ organic food beliefs, demographics and values. British Food Journal, 107(11), 855-869.

Losasso, C., Cibin, V., Cappa, V., Roccato, A., Vanzo, A., Andrighetto, I., \& Ricci, A. (2012). Food safety and nutrition: Improving consumer behavior. Food Control, 26, 252-258. 
MAGRAMA (2008). Guía de buenas prácticas para la producción y comercialización de alimentos ecológicos. Ministerio de Medio Ambiente y Rural y Marino.

MAGRAMA (2013). El consumo alimentario en España. Base de datos. Ministerio de Agricultura, Alimentación y Medio Ambiente, Madrid. http://www.magrama.gob.es/es/alimentacion/temas/consumo-y-comercializaciony-distribucion-alimentaria/panel-de-consumo-alimentario/base-de-datos-deconsumo-en-hogares (Accessed 20th January 2014)

Mann, S., Ferjani, A., \& Reissig, L. (2012). What matters to consumers of organic wine? British Food Journal, 114, 272-184.

McFadden, D. (1974). Conditional logit analysis of qualitative choice behavior. New York: Academic Press.

McFadden, D. (1986). The Choice Theory Approach to Market Research. Marketing Science 5(4), 275-97.

Menapace, L., Colson, G., Grebitus, C., \& Facendola, M. (2011). Consumers' preferences for geographical origin labels: evidence from the Canadian olive oil market. European Review of Agricultural Economics, 38, 1-20.

MINTEL (2015). Global New Products Database (GNPD). www.gndp.com (accessed $8^{\text {th }}$ October, 2015)

Montgomery, D.C. (2001). Design and analysis of experiments. Fifth edition. New York: John Wiley \& Sons.

Moore, D.G. (1963). Lifestyle in Mobile Suburbia. In Greyser, S.A. (Ed.) Towards scientific marketing (pp. 243-266). American Marketing Association, Chicago, II.

Nocella, G., Boecker, A., Hubbard, L., \& Scarpa, R. (2012). Eliciting consumer preferences for certified animal-friendly foods: can elements of the theory of planned behavior improve choice experiment analysis? Psychology and Marketing, 29(11): 850-868.

Philippidis, G., Kakaroglou, I., \& Sanjuan A. (2002). Territorial product association in Greece: The case of olive oil. Paper presented at the Xth EAAE Congress, Zaragoza, 28-31 August.

Revelt, D., \& Train, K. (1998). Mixed Logit with Repeated Choices: Households' Choices of Appliance Efficiency Level. Review of Economics and Statistics, 80, 647-657. 
Roitner-Schobesberger, B., Darnhofer, I., Somsook, S., \& Vogl, C.R. (2007) Consumer perceptions of organic foods in Bangkok, Thailand. Food Policy, 33(2), 112-121.

Ruiz-Castillo, B. (2008). Las denominaciones de origen protegidos y el aceite de oliva en España. Distribución y Consumo, 57-68.

Rungie, C.M., Coote, L.V., \& Louviere, J.J. (2011). Structural choice modelling: theory and applications to combining choice experiments. Journal of Choice Modelling, 4, 1-29.

Rungie, C.M., Coote, L.V., \& Louviere, J.J. (2012). Latent variables in discrete choice experiments. Journal of Choice Modelling, 5, 145-156.

Scarpa, R., \& Del Guidice, T. (2004). Market segmentation via mixed Logit: extra virgin olive oil in urban Italy. Journal of Agriculture and Food Industrial Organization, 2, 1-20.

Scarpa, R., and Thiene, M. (2011). Organic food choices and protection motivation theory: addressing the psychological sources of heterogeneity. Food Quality and Preference, 22, 532-541.

Shaharudin, M.R., Pani, J.J., Mansor, S.W., \& Elias, S.J. (2010). Factors affecting purchase intention of organic food in Malaysia’s Kedah state. Cross-Cultural Communication, 6, 105-121.

Soler, F., Gil., J.M., \& Sánchez, M. (2002). Consumer’s acceptability of organic food in Spain. Results from an experimental auction market. British Food Journal, 104, 670-687.

Street, D. \& Burgess, L.B. (2007). The construction of optimal stated choice experiments: theory and methods. New Jersey: Hoboken.

Train, K. (2003). Discrete choice methods with simulation. New York: Cambridge University Press.

Tsakiridou, E., Mattas, K., \& Tzimitra-Kalogianni, I. (2006). The influence of consumer characteristics and attitudes on the demand for organic olive oil. Journal of International Food \& Agribusiness Marketing, 1, 23-31.

Van den Horst, K. et al. (2010). Ready-meal consumption: associations with weight status and cooking skills. Public Health Nutrition, 14, 239-245.

Vega-Zamora, M., Parras-Rosa, M., Torres-Ruiz, F.J., \& Murgado-armenteros, E.M. (2011). Los factores impulsores e inhibidores del consumo de alimentos ecológicos en España. El caso del aceite de oliva. ITERCIENCIA, 36, 178-184. 
783 Walker, J. \& Ben-Akiva, M. (2002). Generalized random utility model. Mathematical $784 \quad$ Social Sciences, 43, 303-343.

785 Wells, W. D., \& Tigert, D. J. (1971) Attitudes, Interests and Opinions, Journal of $786 \quad$ Advertising Research, 11, 27-35.

787 Yañez, M.F., Raveau, J., \& Ortúzar, J.D. (2010). Inclusion of latent variables in mixed 788 logit models: modelling and forecasting. Transport Research Part A, 44, 774-753. 789 
790 Table 1 New olive oil products launched in the world food market from 2011 to 2013

\begin{tabular}{|c|c|c|}
\hline Country & Number of products launched & Percentage \\
\hline USA & 167 & 15.0 \\
\hline Brazil & 129 & 11.6 \\
\hline Italy & 73 & 6.5 \\
\hline France & 54 & 4.8 \\
\hline Germany & 51 & 4.6 \\
\hline Mexico & 48 & 4.3 \\
\hline Spain & 42 & 3.8 \\
\hline India & 38 & 3.4 \\
\hline Australia & 34 & 3.1 \\
\hline Chile & 32 & 2.9 \\
\hline Colombia & 32 & 2.9 \\
\hline Argentina & 30 & 2.7 \\
\hline UK & 29 & 2.6 \\
\hline South Africa & 27 & 2.4 \\
\hline Venezuela & 26 & 2.3 \\
\hline Russia & 25 & 2.2 \\
\hline Finland & 22 & 2.0 \\
\hline Greece & 20 & 1.8 \\
\hline Canada & 19 & 1.7 \\
\hline Austria & 17 & 1.5 \\
\hline Egypt & 15 & 1.3 \\
\hline Hong Kong & 13 & 1.2 \\
\hline Saudi Arabia & 13 & 1.2 \\
\hline Ukraine & 13 & 1.2 \\
\hline New Zealand & 12 & 1.1 \\
\hline Thailand & 12 & 1.1 \\
\hline Turkey & 12 & 1.1 \\
\hline Czech Republic & 11 & 1.0 \\
\hline Netherlands & 11 & 1.0 \\
\hline Sweden & 11 & 1.0 \\
\hline Vietnam & 11 & 1.0 \\
\hline Portugal & 10 & 0.9 \\
\hline China & 9 & 0.8 \\
\hline South Korea & 9 & 0.8 \\
\hline Israel & 6 & 0.5 \\
\hline Norway & 4 & 0.4 \\
\hline Poland & 4 & 0.4 \\
\hline Singapore & 4 & 0.4 \\
\hline Switzerland & 4 & 0.4 \\
\hline Taiwan & 4 & 0.4 \\
\hline Belgium & 3 & 0.3 \\
\hline Denmark & 3 & 0.3 \\
\hline Indonesia & 2 & 0.2 \\
\hline Ireland & 2 & 0.2 \\
\hline Hungary & 1 & 0.1 \\
\hline Malaysia & 1 & 0.1 \\
\hline Philippines & 1 & 0.1 \\
\hline Total & 1116 & 100.0 \\
\hline
\end{tabular}

791 Source: MINTEL (2015). Global New Products Database (GNPD)

792 
794 Table 2 Attributes and attribute levels in the Choice Experiment

\begin{tabular}{c|c}
\hline Attributes & Levels \\
\hline Production system & Conventional \\
& Organic \\
\hline Origin & Spain \\
& Catalonia \\
& Imported \\
\hline Brand & Spanish manufacturer \\
& Catalonia manufacturer \\
& Private label \\
\hline Price & $\mathbf{3 . 7 0} € / \mathbf{l}$ \\
& $\mathbf{6} € / \mathbf{l}$ \\
& $\mathbf{7 . 5} € / \mathbf{l}$ \\
\hline
\end{tabular}

795

796

797

798

799

800

801

802

803

804

805

806

807

808

809

810

811

812 
813 Table 3. Results from the Structural Equation Model (SEM) to explain consumer's purchasing 814 intentions towards organic olive oil

\begin{tabular}{|c|c|c|c|c|}
\hline Structural relationships & $\begin{array}{l}\text { Parameter } \\
\text { Estimate }\end{array}$ & Std error & $R^{2}$ & $\begin{array}{l}\text { Goodness } \\
\text { of fit statistics }\end{array}$ \\
\hline Attitude $\rightarrow$ Food Involvement & $0.299^{* * *}$ & 0.0653 & 0.329 & \\
\hline Attitude $\rightarrow$ Healthy Life Style & -0.0784 & 0.0701 & & \\
\hline Attitude $\rightarrow$ Ordered Life Style & $0.384^{* * *}$ & 0.0825 & & $\chi 2=2021.270$ \\
\hline Attitude $\rightarrow$ Cooking Skills & 0.033 & 0.0575 & & $\mathrm{df}=741$ \\
\hline $\begin{array}{l}\text { Perceived Behavioural Control } \rightarrow \\
\text { Knowledge }\end{array}$ & $0.248^{* * *}$ & 0.0655 & 0.318 & $\begin{array}{l}\mathrm{NC}=2.727<3 \\
\mathrm{RMSEA}=0.0658<0.08\end{array}$ \\
\hline $\begin{array}{l}\text { Perceived Behavioural Control } \rightarrow \text { Price } \\
\text { Involvement }\end{array}$ & $0.234^{* * *}$ & 0.0549 & & $\begin{array}{l}\mathrm{CFI}=0.952>0.90 \\
\mathrm{NFI}=0.926>0.90\end{array}$ \\
\hline $\begin{array}{l}\text { Perceived Behavioural Control } \rightarrow \text { Quality } \\
\text { Involvement }\end{array}$ & $0.491^{* * *}$ & 0.0532 & & $\begin{array}{l}\text { NNFI }=0.946>0.90 \\
\mathrm{IFI}=0.952>0.90\end{array}$ \\
\hline Purchase intention $\rightarrow$ Subjective Norm & $0.167^{* * *}$ & 0.0351 & 0.623 & $\mathrm{RFI}=0.918>0.90$ \\
\hline Purchase intention $\rightarrow$ Attitude & $-0.127^{* * *}$ & 0.0388 & & \\
\hline $\begin{array}{l}\text { Purchase intention } \rightarrow \text { Perceived } \\
\text { Behavioural Control }\end{array}$ & $0.772^{* * *}$ & 0.0559 & & \\
\hline
\end{tabular}

815 Notes : ${ }^{* * *} \mathrm{p}<0.01$; $^{* *} \mathrm{p}<0.05 ;{ }^{*} \mathrm{p}<0.1$ 
817 Table 4. Estimated parameters from the Random parameter Logil (RPL)

\begin{tabular}{|c|c|c|}
\hline Parameters & RPL & Standard error \\
\hline${\text { Conventional }(\mathrm{CONV})^{1}}^{1}$ & 1.280 & ---- \\
\hline Denominated Origin Protected (DOP) & $0.251^{* * *}$ & 0.039 \\
\hline Organic (ORG) & $-1.531^{* * *}$ & 0.253 \\
\hline Spanish origin (OSP) ${ }^{1}$ & 0.178 & ---- \\
\hline Catalan origin (OCAT) & $0.490^{* * *}$ & 0.036 \\
\hline Imported origin (OIMP) & $-0.668^{* * *}$ & 0.045 \\
\hline Spanish manufacturer (MSP) ${ }^{1}$ & 0.074 & ---- \\
\hline Catalan manufacturer (MCAT) & -0.005 & 0.050 \\
\hline Private brand (PRB) & -0.069 & 0.055 \\
\hline Price & $-0.868^{* * *}$ & 0.027 \\
\hline No option (NOP) & $-3.265^{* * *}$ & 0.818 \\
\hline Attitude (ATT) & --- & --- \\
\hline Behavioral Control Prception (BCP) & ---- & ---- \\
\hline Subjective Norm (SBN) & ---- & ---- \\
\hline Orderly lifestyle (OLS) & -0.240 & 0.515 \\
\hline Healthy lifestyle (HLS) & $-0.820^{* *}$ & 0.282 \\
\hline Price Involvement (PIN) & $1.587^{* * *}$ & 0.430 \\
\hline Quality involvement (QIN) & $1.505^{* *}$ & 0.537 \\
\hline Food involvement (FIN) & $1.022^{* *}$ & 0.463 \\
\hline Cooking-Skills (COS) & $-2.408^{* * *}$ & 0.435 \\
\hline & standard deviations & Standard error \\
\hline DOP & $0.410^{* * * *}$ & 0.032 \\
\hline ORG & $0.733^{* * *}$ & 0.049 \\
\hline OCAT & $0.765^{* * *}$ & 0.034 \\
\hline Price & $0.794^{* * *}$ & 0.030 \\
\hline OLS & $0.261^{* * *}$ & 0.024 \\
\hline HLS & $0.549^{* * *}$ & 0.035 \\
\hline PIN & 0.012 & 0.012 \\
\hline QIN & $0.504^{* * * *}$ & 0.041 \\
\hline FIN & Fixed Parameter & ---- \\
\hline $\cos$ & $0.149^{* *}$ & 0.049 \\
\hline Parameter-Variable & Heterogeneity in mean & Standard error \\
\hline ORG-ATT & $0.276^{* * * *}$ & 0.039 \\
\hline ORG-BCP & $-0.093^{* *}$ & 0.041 \\
\hline ORG-SBN & $0.190^{* * *}$ & 0.033 \\
\hline OLS-SECOND & $-0.511^{* *}$ & 0.239 \\
\hline OLS-UNIV & -0.353 & 0.323 \\
\hline OLS-GEND & $-0.854^{*}$ & 0.469 \\
\hline OLS-TS & $1.804^{* * *}$ & 0.449 \\
\hline HLS-SECOND & $0.661^{* * *}$ & 0.155 \\
\hline HLS-GEND & $1.002^{* * *}$ & 0.243 \\
\hline HLS-TS & $-2.070^{* * *}$ & 0.284 \\
\hline HLS-AGE & $1.198^{* * *}$ & 0.230 \\
\hline PIN-UNIV & $-0.881^{* *}$ & 0.290 \\
\hline PIN-GEND & $-1.198^{* *}$ & 0.375 \\
\hline PIN-TS & $0.779^{* *}$ & 0.347 \\
\hline PIN-AGE & $-0.491^{*}$ & 0.278 \\
\hline QIN-SECOND & $1.820^{* * * *}$ & 0.287 \\
\hline QIN-UNIV & $-0.761^{* *}$ & 0.382 \\
\hline QIN-GEND & $-1.646^{* *}$ & 0.501 \\
\hline QIN-TS & $-1.072^{*}$ & 0.583 \\
\hline FIN-SECOND & $-1.635^{* * *}$ & 0.247 \\
\hline FIN-UNIV & $0.730^{* *}$ & 0.352 \\
\hline FIN-GEND & $0.964^{* *}$ & 0.384 \\
\hline FIN-AGE & $-2.241^{* * *}$ & 0.384 \\
\hline COS-SECOND & $0.405^{*}$ & 0.233 \\
\hline COS-UNIV & $1.425^{* * *}$ & 0.298 \\
\hline COS-GEND & $1.009^{* *}$ & 0.427 \\
\hline COS-AGE & $2.689^{* * *}$ & 0.413 \\
\hline \multicolumn{3}{|c|}{ Goodness-of-fit } \\
\hline L-likelihood & \multirow{2}{*}{\multicolumn{2}{|c|}{$\begin{array}{c}-2903.046 \\
0.41527\end{array}$}} \\
\hline R2 adjs & & \\
\hline
\end{tabular}


824 Figure 1. World olive oil production and consumption 1993-2014 (main countries)

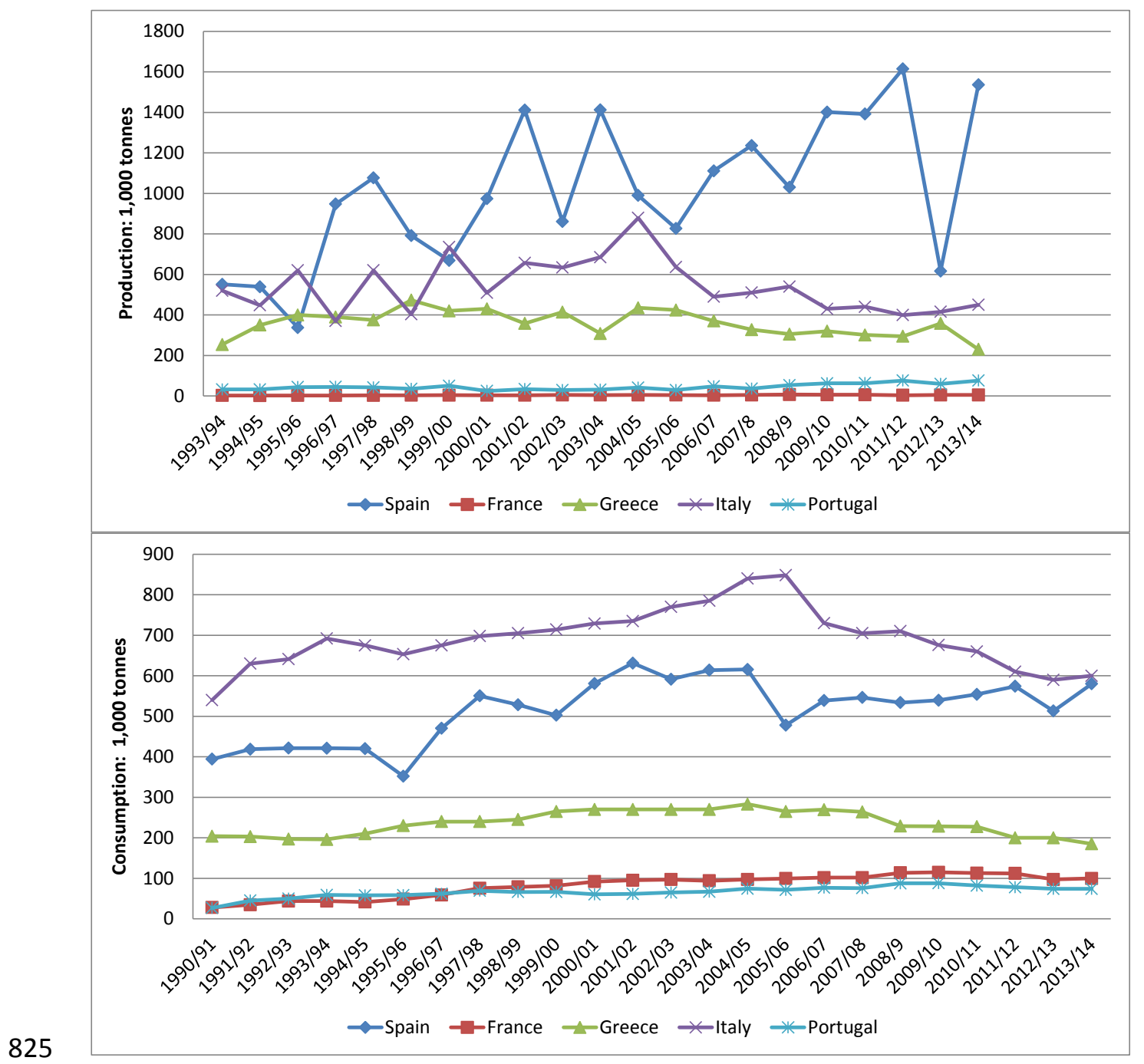

826 Note: 2012/13 data are provisional and 2013/14 data are estimated.

827 Source: Data from the international olive oil council (November 2013). 
Figure 2. A conceptual model to understand organic olive oil purchase intention.

830

831

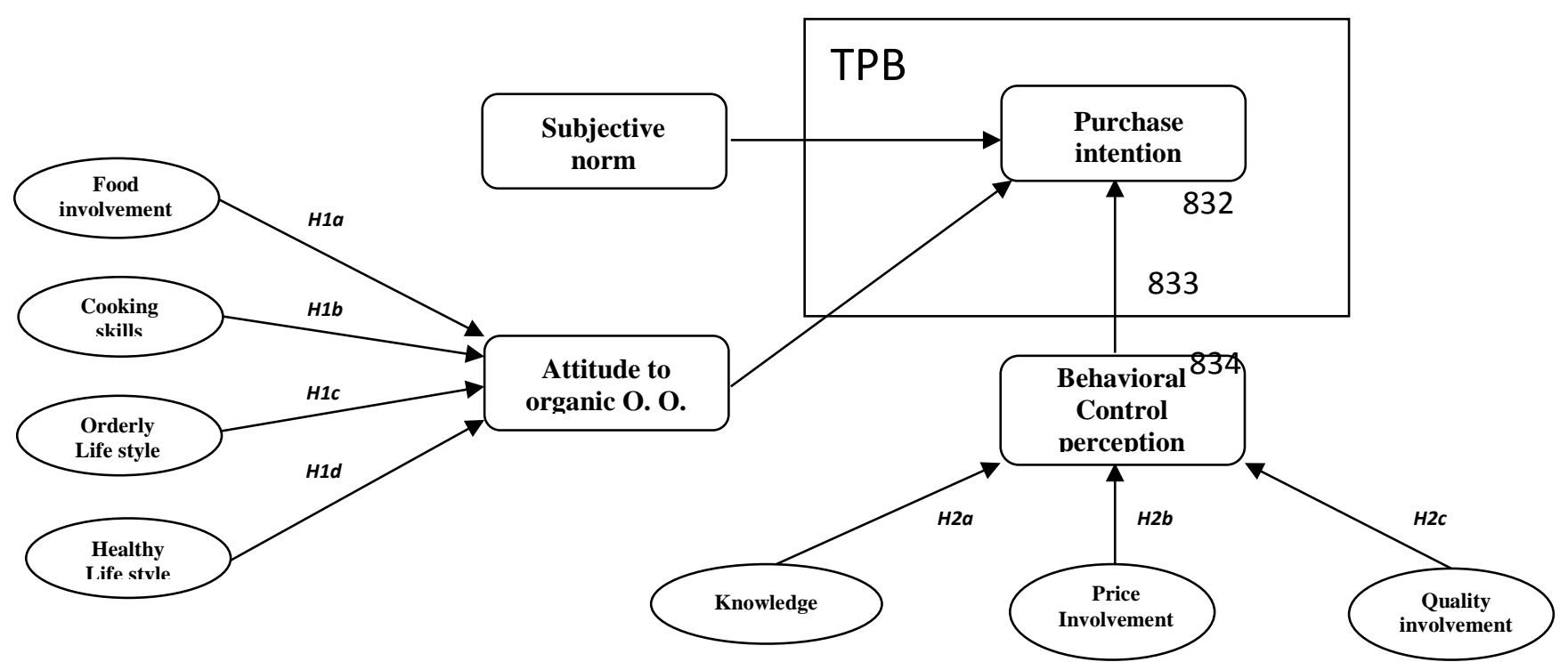

835

836

837

838

839

840

841

842

843

844

845

846

847

848

849

850

851 
852 Figure 3. Example of a choice set

\begin{tabular}{|c|c|c|c|c|}
\hline & Alternative " $A$ " & Alternative " $B$ " & Alternative " $C$ " & Alternative "D" \\
\hline$\frac{\text { System of }}{\text { production }}$ & $\begin{array}{c}\text { Extra-virgin olive } \\
\text { oil with PDO }\end{array}$ & $\begin{array}{c}\text { Conventional } \\
\text { extra-virgin olive } \\
\text { oil }\end{array}$ & $\begin{array}{l}\text { Organic extra- } \\
\text { virgin olive oil }\end{array}$ & \multirow{4}{*}{ None of them } \\
\hline $\begin{array}{l}\text { Origin } \\
\text { of olive oil }\end{array}$ & Spain & Catalonia & Imported & \\
\hline Brand & $\begin{array}{c}\text { Spanish } \\
\text { Manufacturer }\end{array}$ & private label & $\begin{array}{c}\text { Catalonia } \\
\text { Manufacturer }\end{array}$ & \\
\hline$\underline{\text { Price }}$ & $3.70 € /$ liter & $7.50 € /$ liter & $6 € /$ liter & \\
\hline
\end{tabular}

853

854

855

856

857

858 
859 Appendix A

860 Table A1. Confirmatory factor Analysis on personality traits

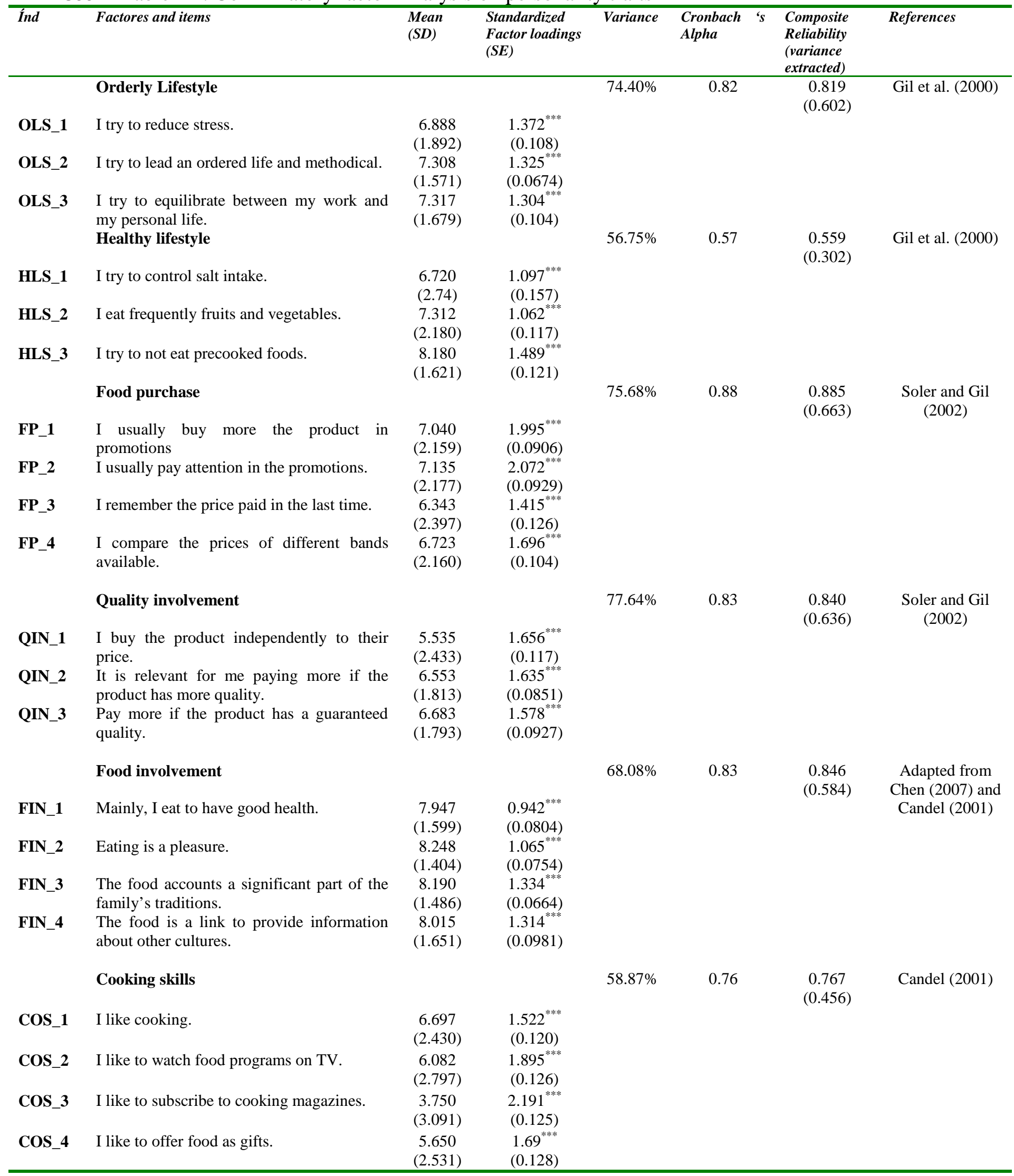

861 Notes : ${ }^{* * *} \mathrm{p}<0.01 ; * * \mathrm{p}<0.05 ;{ }^{*} \mathrm{p}<0.1$; SD: Standard Deviation; SE: Standard Error. 
862 Table A2. Confirmatory factor Analysis on Behavioral factors

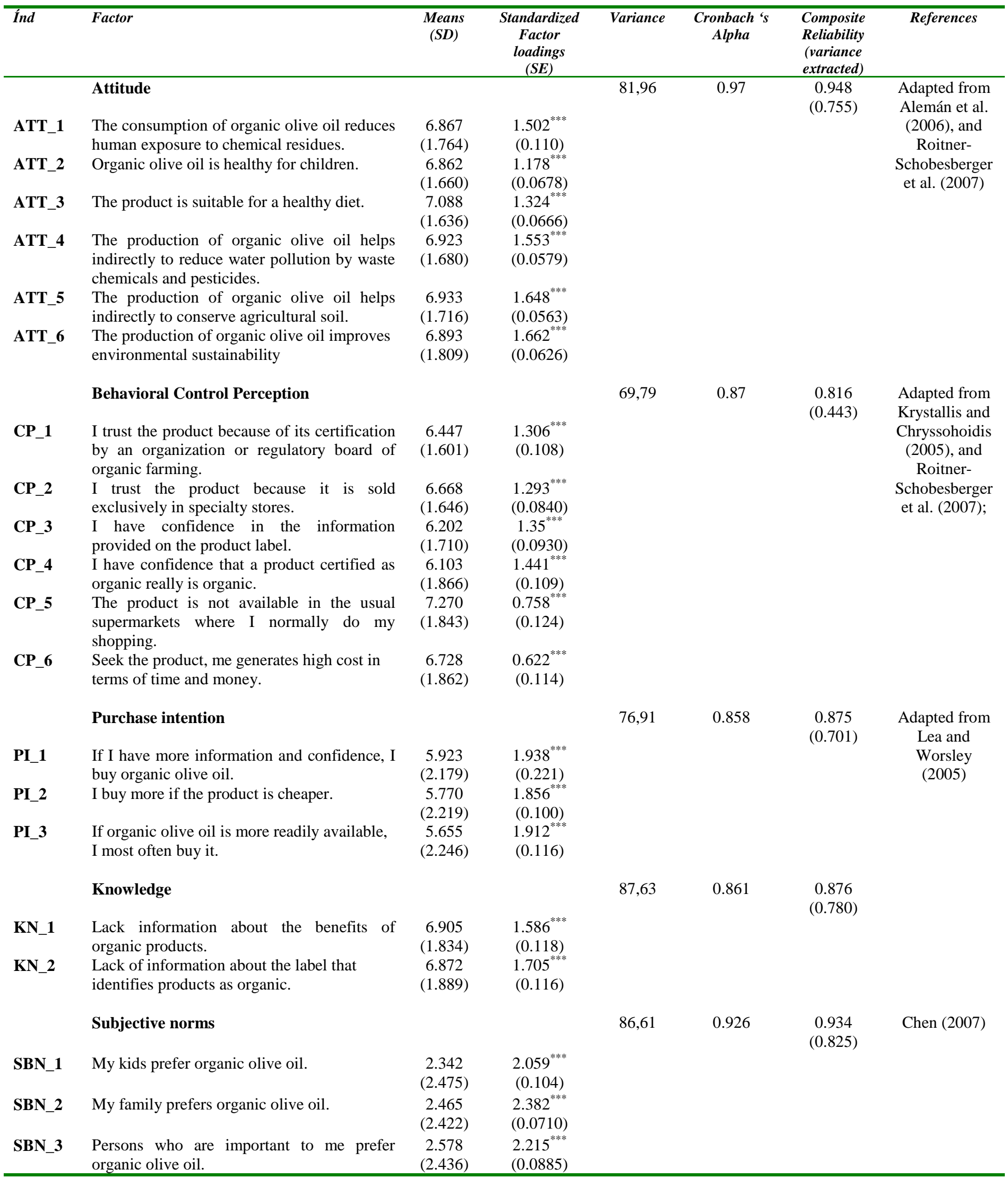

863 Notes : ${ }^{* * *} \mathrm{p}<0.01 ;{ }^{* *} \mathrm{p}<0.05 ;{ }^{*} \mathrm{p}<0.1$; SD: Standard Deviation; SE: Standard Error. 